\title{
Heparanase upregulation from adipocyte associates with inflammation and endothelial injury in diabetic condition
}

\author{
Nur Arfian*, Wiwit Ananda Wahyu Setyaningsih, Muhammad Mansyur Romi and Dwi Cahyani Ratna Sari
}

From 3rd International Symposium on Congenital Anomaly and Developmental Biology 2019

Yogyakarta, Indonesia. 8-9 August 2019

\begin{abstract}
Background: Diabetes Mellitus (DM) is one of the metabolic diseases which leads to fatty tissue injury, and consequently inducing lipotoxicity and cellular senescence. This condition contributes to endothelial dysfunction with chronic inflammation and organ damage. Heparanase which has a role in disrupting endothelial surface layer (glycocalyx) may promote endothelial Nitric oxide synthase (eNOS) reduction and inflammation. However, its relationship with DM and organ injury has not been fully elucidated yet. This study aimed to determine how heparanase from fatty tissue may contribute to endothelial dysfunction and inflammation in patients with hyperglycemia and in a hyperglycemia model in rats.
\end{abstract}

Methods: This population study with a cross-sectional design was conducted with 28 subjects without diagnosis and medication of DM. Fasting blood glucose levels, lipid profile, heparanase protein, MCP-1 protein and HbA1c were quantified. In vivo study was performed with a diabetic model in Wistar rats induced with streptozotocin $60 \mathrm{mg} / \mathrm{kg}$ body weight by single intraperitoneal injection. Rats were euthanized after 1 month (DM1 group, $n=6$ ), 2 months (DM2 group, $n=6$ ) and 4 months (DM4 group, $n=6$ ). White Adipose Tissue (WAT) was harvested from visceral fat. Real Time and Reverse Transcriptase-PCR (RT-PCR) was done to quantify expressions of heparanase, MCP-1, eNOS, IL-6 and p-16 (senescence). Immunostaining was performed to localize MCP-1 and macrophage (CD68). Western blot tests were used to examine eNOS, MCP-1 and heparanase protein expression.

Results: This study revealed associations between blood glucose levels with higher HbA1c, LDL, cholesterol, heparanase and MCP-1. The in vivo study also revealed lipid levels as the source of Heparanase and MCP-1 mRNA and protein expressions. This finding was associated with inflammation, cellular senescence and macrophage infiltration in fat tissue based on immunostaining and qRT-PCR analysis. RT-PCR revealed significantly lower expression of eNOS and higher expression of IL-6 in DM groups compared to the control group.

Conclusion: Heparanase upregulation in fat tissue was associated with endothelial injury and inflammation in hyperglycemia conditions.

Keywords: Diabetes mellitus, Heparanase, MCP-1, Inflammation, Endothelial injury

\footnotetext{
*Correspondence: nur_arfian@ugm.ac.id

Department of Anatomy, Faculty of Medicine, Public Health, and Nursing,

Universitas Gadjah Mada, Yogyakarta, Indonesia
}

(c) The Author(s). 2019 Open Access This article is distributed under the terms of the Creative Commons Attribution 4.0 International License (http://creativecommons.org/licenses/by/4.0/), which permits unrestricted use, distribution, and reproduction in any medium, provided you give appropriate credit to the original author(s) and the source, provide a link to the Creative Commons license, and indicate if changes were made. The Creative Commons Public Domain Dedication waiver (http://creativecommons.org/publicdomain/zero/1.0/) applies to the data made available in this article, unless otherwise stated. 


\section{Background}

Type 2 Diabetes Mellitus (T2DM) is a metabolic disorder that causes increased morbidity and mortality every year. Worldwide, the number of patients with T2DM is expected to double by 2030 [1]. Indonesia was recognized among the ten highest global prevalence of DM in 2000, and is likely to maintain that status until 2030 [2]. Obesity is one of the main risk factors that leads to the T2DM development. Obesity induces leptin upregulation, adiponectin downregulation and resistin upregulation, which consequently leads to unhealthy metabolism changes. Those alterations include adipocyte hypertrophy which induces increases in free fatty acid levels. All of these phenomena are involved in lipotoxicity [3].

Lipotoxicity induces glucose homeostasis alterations due to failure of insulin signaling [4, 5]. Increased changes in metabolism in obesity and lipotoxicity bring upregulation of proinflammatory cytokines, chemokines and growth factors. These conditions may lead to macrophage infiltration and production of induciblenitrite oxide synthase (iNOS), and oxidative stress (free radicals) [4]. Furthermore, obesity causes hyperinsulinemia, as a consequence of insulin resistance and hyperglycemia. Hyperglycemia becomes the origin of metabolic and structural disruptions, including increased production of reactive oxygen species (ROS), advance-glycation end products (AGE), and disruption of renin-angiotensin system (RAS) regulation [6, 7].

Diabetes mellitus type 2 is an important contributor to the occurrence of microvascular injury and organ dysfunction. The mechanism is based on the presence of sterile chronic inflammation, and cellular senescence. Senescence cells produce senescence-associated secretory phenotype (SASP) factors, including chemokines, proteases, proinflammatory cytokines, growth factors, macrophage inflammatory proteins (MIPs), and granulocyte-macrophage colony-stimulating factors (GM-CSFs) [7, 8]. The SASP components, such as interleukin (IL)-6, IL-8, and MCP-1, are elevated in obese adults and adolescents and may contribute to proinflammatory conditions. Another SASP component, PAI-1 is known to increase in circulation and tissue, as in coronary arteries [7]. Fat cells (adipocytes) play an important role in the pathogenesis of DM. These cells undergo accelerated senescence and induce injury to other cells, especially endothelial cells in the micro blood vessels. This suggests that endothelial cells are the key organ that plays a role in the pathophysiology of diabetic complications [9]. Endothelial injury may lead to complication of DM, such as ischemic reperfusion injury conditions, such as stroke, acute myocardial infarction, peripheral arterial diseases and kidney ischemic/reperfusion injury (IRI).

Endothelial injury can be induced by perfusion disturbance, such as in kidney ischemic/reperfusion injury
[10]. Ischemic and hypoxic conditions in other organs, such as heart and liver also lead to endothelial damage with a disruption of glycocalyx [11-14]. In the kidney diseases, glycocalyx disruption and shedding have been already known occur in inflammation and ischemic condition [15, 16], albuminuria and microvascular permeability [17] and adriamycin nephropathy [18]. Glycocalyx is composed by proteoglycan components consisting of heparan sulphate and chondroitin sulphate. Among proteoglycan, heparan sulphate (HS) is the most common glycosaminoglycan (GAG) in the endothelial cell (EC), constitute $40-50 \%$ of EC glycocalyx [16]. HS loss is also induced by heparanase production, an endoglycosidase that degrades HS [19]. Our previous study revealed upregulation of heparanase in kidney ischemic reperfusion injury model, which associated with reduction of eNOS protein expression and degradation of endothelial surface layer/glycocalyx. Heparanase upregulation with eNOS reduction and Endothelin-1 elevation also occurred in hypoxic endothelial cells culture. This associated with upregulation of Intercellular Adhesion Molecule-1 (ICAM-1) [20]. Heparanase have been reported play roles in cancer metastasis and invasion through interstitial remodeling [21-24]. It also plays role in renal diseases induced by hyperglycemia and diabetes $[25,26]$. So far, there is no report about the expression of heparanase in prediabetic to diabetic condition in correlation with endothelial injury, inflammation and lipid profiles. This study elucidate expression of heparanase in prediabetic and diabetic condition with obese population. We also confirmed heparanase expression in diabetic mellitus model in rats.

\section{Methods}

\section{Subject characteristics}

This research was a cross-sectional population study. Fasting blood samples were collected from an obese population involving 24 subjects, consisting of females with ages 41-89 years old and living in the rural area of Bantul, Yogyakarta. Inclusion criteria were: subjects without diagnosis of DM and no medication of DM and willing to participate in the study. Exclusion criteria were patients with chronic diseases, DM medication, and who refused to join the study. All subjects completed informed consent forms. The study was approved by the Medical and Health Research Ethics Committee of the Faculty of Medicine, Public Health and Nursing, Universitas Gadjah Mada, Yogyakarta, Indonesia. All of the subjects were examined for basic anthropometric data including: body weight, height, blood pressure, serum blood glucose and abdominal circumstance. Abdominal circumference (AC) was used to determine obese patients with $\mathrm{AC}>80 \mathrm{~cm}$. 


\section{Study groups}

Subjects were divided into 4 groups based on their Body Mass Index (BMI). Group K1 consisted of subjects with normal BMI and fasting blood glucose (FBG) less than $100 \mathrm{mg} / \mathrm{dL}$ (normal, $n=10$ ), group K2 were subjects with $\mathrm{AC}>80$ and FBG less than 100 (normal, $n=10$ ), group K3 were subjects with $\mathrm{AC}>80$ (obese) and FBG 100$125 \mathrm{mg} / \mathrm{dL}$ (prediabetic condition, $n=10$ ), while $\mathrm{K} 4$ group included subjects with $\mathrm{AC}>80 \mathrm{~cm}$ (obese) and FBG $>125 \mathrm{mg} / \mathrm{dL}(\mathrm{n}=10)$. Nearly 100 people were examined in a countryside population for screening of diabetes and obesity. Subjects diagnosed as obese $(\mathrm{AC}>80)$ were included in the study. Subject who have already diagnosed diabetes mellitus and got medication were excluded from the study. After explanation of the research objectives and informed consent, patients were checked for fasting blood analysis.

\section{Blood serum analysis}

Fasting blood samples were taken from the subjects as much as $4.5 \mathrm{~mL}$ and kept in vacutainer with EDTA for anti-coagulant. Serum was made using centrifugation with $10,000 \mathrm{rpm}$ for $10 \mathrm{~min}$ in $4{ }^{\circ} \mathrm{C}$ temperature. Serum was kept in $-80^{\circ} \mathrm{C}$. Lipid profiles (LDL, Triglycerides, HDL, and Cholesterol) were quantified in a clinical laboratory using standard methods.

\section{Heparanase, monocyte chemoattractant protein-1 and HbA1c quantification}

Serum was also used for quantification of heparanase (Finetest, EH1020), Monocyte chemoattractant protein-1 (MCP-1) (Finetest, EH022) using ELISA kit. All of the procedures were based on instruction manual of the kit. Level of HbA1c was also examined in clinical laboratory using standard method.

\section{Animal model of diabetes mellitus (DM)}

A total of 24 male Sprague Dawley mice age 3-4 months were used in this study. Rats were placed in cages with a light-dark cycle of $12 \mathrm{~h}$. DM model was induced with single intraperitoneal injection of Streptozotocin (Nacalai, 32,238-91) at $60 \mathrm{mg} / \mathrm{kg}$ body weight. Blood glucose levels were quantified on day 5 after injection to examine the success of the model. DM was defined if the blood glucose level was higher than $200 \mathrm{mg} / \mathrm{dL}$. Rats were divided based on the time of euthanasia, 1 month (DM1 group, $n=7$ ), 2 months (DM2 groups, $\mathrm{n}=7$ ), 4 months (DM4 group, $\mathrm{n}=7$ ). The control group was injected with $\mathrm{NaCl} 0.9 \%$ for single dose, then euthanized after 4 months.

For euthanasia methods, rats were anaesthetized using ketamine at a dose of $60-100 \mathrm{mg} / \mathrm{kg}$ BW intramuscularly (i.m.). Abdomen and thorax were opened after deep anaesthesia, and the left ventricle was perfused with $\mathrm{NaCl}$
$0.9 \%$. Visceral fat tissues were harvested from intraperitoneal and perirenal areas, then kept in Normal Buffer Formalin for paraffin making and RNA preservation solution for RNA extraction.

RNA extraction, cDNA synthesis and reverse transcriptasepolymerase chain reaction (RT-PCR)

The RNA from fat tissues were extracted using Genezol solution (GENEzol ${ }^{\mathrm{T \mu}}$, Cat No. GZR100) based on the manufacturer's protocol. RNA concentrations were quantified using a nanodrop. The synthesis of RNA to cDNA was done using ReverTra Ace ${ }^{\oplus}$ (Toyobo, Cat. No. TRT-101), deoxyribonucleotide triphosphate (dNTP) (Takara, Cat. No. 4030), and primary random (TAKARA, Cat No. 3801).

Reverse Transcriptase-PCR (RT-PCR) was performed for these following genes with specific primers: heparanase (forward: 5'-CGAACGTCTATCACCCAAGGT-3').; reverse: 5'-AGAACCGAAAGGCTTCAGCA-3').), eNOS (forward: 5-CCGGCGCTACGAAGAATG-3'); reverse: 5'-AGTGCC ACGGATGGAAATT-3').), Interleukin-6 (forward: $5^{\prime}$ TTGGATGGTCTTGGTCCTTAGCC-3'); reverse: 5' TCCTACCCCAACTTCCAATGCTC-3').) and a housekeeping gene, ß-actin (forward 5' - GCAGATGTGGATCA GCAAGC-3' and reverse 5'-GGTGTAAAACGCAGCTCA GTAA-3'). The PCR was performed using the following condition: initial denaturation $94{ }^{\circ} \mathrm{C}$ for $2 \mathrm{~min}$, the following steps were repeated for 35 cycles (denaturation $94{ }^{\circ} \mathrm{C}$ for $20 \mathrm{~s}$, annealing $60^{\circ} \mathrm{C}$ for 20 , elongation $72{ }^{\circ} \mathrm{C}$ for $1 \mathrm{~min}$ ), and last extension $72^{\circ} \mathrm{C}$ for $10 \mathrm{~min}$.

For RT-PCR, we used Taq Master Mix (GoTaq ${ }^{\circ}$ Green Master Mix, Cat No. M7122). PCR products were analyzed on $2 \%$ agarose gel with DNA ladder (Bioron, Germany, Cat No. 306009). Gene expression was quantified with densitometric analysis using Image J software and GAPDH was used to normalize expression.

\section{Immunohistochemical (IHC) staining of MCP-1 and CD68 from visceral adipose tissue}

The visceral adipose tissue from intraperitoneal were made for paraffin, the slides were deparaffinized, then heated incitrate buffer, incubated with 3\% $\mathrm{H} 2 \mathrm{O} 2$ in PBS for endogenous peroxidase inhibition and incubated with blocking solution. Furthermore, the slides were incubated with anti-CD68 (1/100 dilution, Abcam, ab955) and MCP-1 antibody (1/100 dilution, Abcam, ab25124) at $4{ }^{\circ} \mathrm{C}$ overnight. After slides were incubated with species-specific secondary antibodies for $1 \mathrm{~h}$ at room temperature, slides were incubated with avidin-HRP and counter stained with DAB (Biocare, STUHRP700H) complete antigen detection was used avidin-biotinylated complex-horseradish peroxidase before DAB staining. Slide were conterstained with haematoxylin. 


\section{Protein extraction and Western blot}

Protein from adipose tissue was extracted using the ProPrep $^{\text {Tw }}$ (Intron Biotechnology; Cat. No. 17081) from white adipose tissue based on manufacturer instructions. Thirty milligrams of adipose tissues were homogenized with $600 \mu \mathrm{L}$ of Pro-Prep ${ }^{\mathrm{Tw}}$ solution. The homogenates were centrifuged at $12,000 \mathrm{rpm}$ at $4{ }^{\circ} \mathrm{C}$ for $20 \mathrm{~min}$. The supernatants were stored in safe lock tubes at $-80^{\circ} \mathrm{C}$ until they were assayed. A total of $40 \mathrm{~g}$ of protein was separated onto $10 \%$ SDS-PAGE, and transferred to a polyvinylidene fluoride membrane (PVDF) and incubated with antiheparanase (anti-rabbit, 1:500 dilution), Anti-eNOS (antirabbit, 1:300) and anti-MCP-1 (anti-rabbit, 1:1000 dilution). A total of $5 \%$ skim milk in TBST was used for blocking followed by incubation with the appropriate secondary antibody. Proteins were visualized using ECL Prime Western Blotting Detection Reagents (GE Healthcare, RPN2232). Blots were photographed with a Geldoc machine (Geldoc Syngene Gbox Seri Chemi xrq).

\section{Results}

Obese with DM condition associated with higher cholesterol and triglycerides

The K1 group represented normal conditions with normal BMI and normal glucose levels. Meanwhile, K2, K3 and K4 groups represented obese groups with different levels of glucose. Obese subjects in the K2, K3 and K4 groups had significantly higher cholesterol and triglyceride levels compared to $\mathrm{K} 1$, as the representative of normal conditions. However, K2 and K3 groups had significantly higher HDL levels compared to K1. The K4 group had significantly lower HDL level compared to the K2 and K3 groups. This result suggests higher glucose levels might be associated with lower HDL levels (Fig. 1).

\section{Higher glucose levels associated with increased} endothelial dysfunction, heparanase expression and inflammation

Next, we examined HbA1c as marker for glycation of endothelial cells, especially in diabetic condition for showing endothelial function and predicting arterial stiffness and endothelial dysfunction [27]. HbA1c concentration quantification revealed that $\mathrm{K} 4$ group had the highest HbA1c and significant higher compared to $\mathrm{K} 1$, $\mathrm{K} 2$ and $\mathrm{K} 3$ group. K4 group had mean of HbA1c more than 6 as cut point for endothelial injury. LDL level showed $\mathrm{K} 3$ and $\mathrm{K} 4$ groups had significant higher LDL level compared to K1 group, furthermore K4 group represented the highest LDL level. K4 group also had
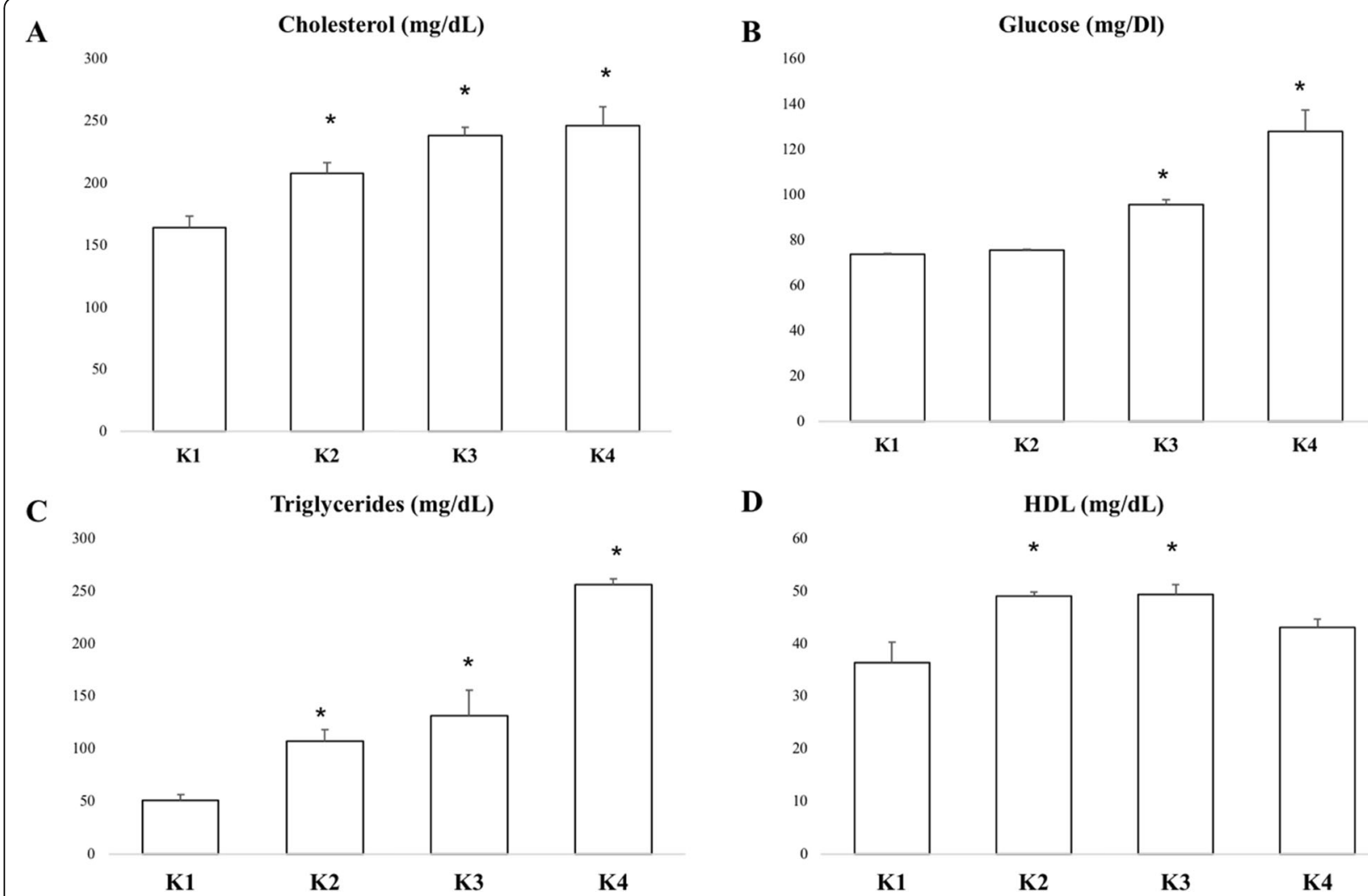

D

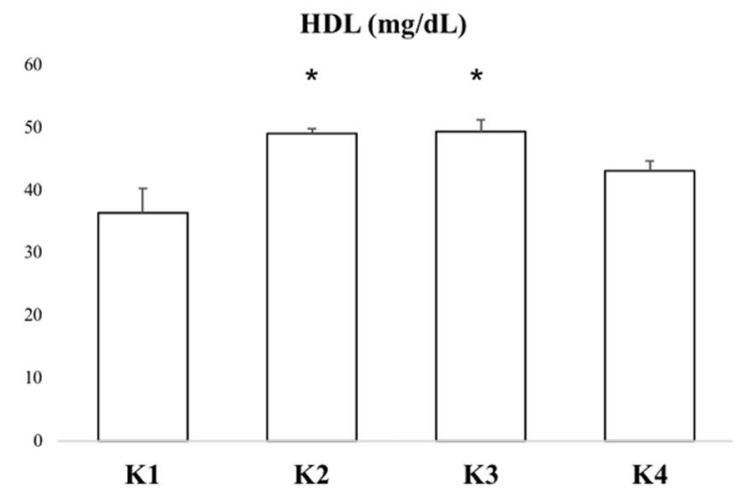

Fig. 1 Mean of cholesterol (a), fasting glucose (b), triglyceride (c) and HDL (d) levels in each group. Higher glucose levels might be associated with higher cholesterol and triglyceride levels 
significant LDL level compared to K2 and K3 groups. It seemed that higher glucose level also associated with higher LDL level (Fig. 2b).

ELISA quantification of heparanase protein showed significantly higher levels in the $\mathrm{K} 2, \mathrm{~K} 3$ and $\mathrm{K} 4$ groups compared to the $\mathrm{K} 1$ group. Interestingly, K3 group which represented prediabetic conditions had the highest heparanase protein levels among the groups. There were also significantly higher levels of heparanase protein in the K3 group compared to the $\mathrm{K} 2$ and K4 groups. Meanwhile, the MCP-1 protein level measurements showed the highest MCP-1 protein level in the K4 group, which was significantly different compared to the $\mathrm{K} 1, \mathrm{~K} 2$ and $\mathrm{K} 3$ groups. There were no significant differences between groups K1, K2 and K3 (Fig. 2c-d).

In vivo experiment showed adipocyte tissue as the source of heparanase and MCP-1

In vivo experiment was conducted to confirm the source of heparanase and inflammation in the hyperglycemic conditions, which in groups DM1, DM2 and DM4 were demonstrated by significantly lower eNOS mRNA expressions compared to the SO group (Fig. 3 a-b). It was also associated with significantly lower IL-6 mRNA expressions as a biomarker of inflammation in the DM4 group, although the results showed that the IL-6 expression was lower in the hyperglycemic groups. However, statistical analysis revealed only the DM4 group had significant differences compared to the SO group.

Real Time-PCR (qRT-PCR) also revealed significantly higher expression of heparanase mRNA expression in adipose tissue of the DM4 group compared to the $\mathrm{SO}$ group. DM4 had the highest heparanase mRNA expression and had significantly higher expression compared to the DM1 and DM2 groups. Western blot analysis was done for representative and confirmation of heparanase, eNOS and MCP-1 expressions. It showed that the hyperglycemic conditions were associated with higher expression of heparanase and MCP-1 in adipocyte tissue. Interestingly, the lower eNOS expression was clearly demonstrated in the DM4 group.

\section{Immunostaining of MCP-1 and macrophage in adipocyte tissue}

Immunostaining of inflammation markers using MCP-1 and CD68 (macrophage) showed positive staining in adipocyte tissue in the hyperglycemic groups. CD68 as a macrophage marker had positive signaling in interstitial areas of the tissue which suggests macrophage infiltration might be induced by hyperglycemic conditions (Fig. 4).

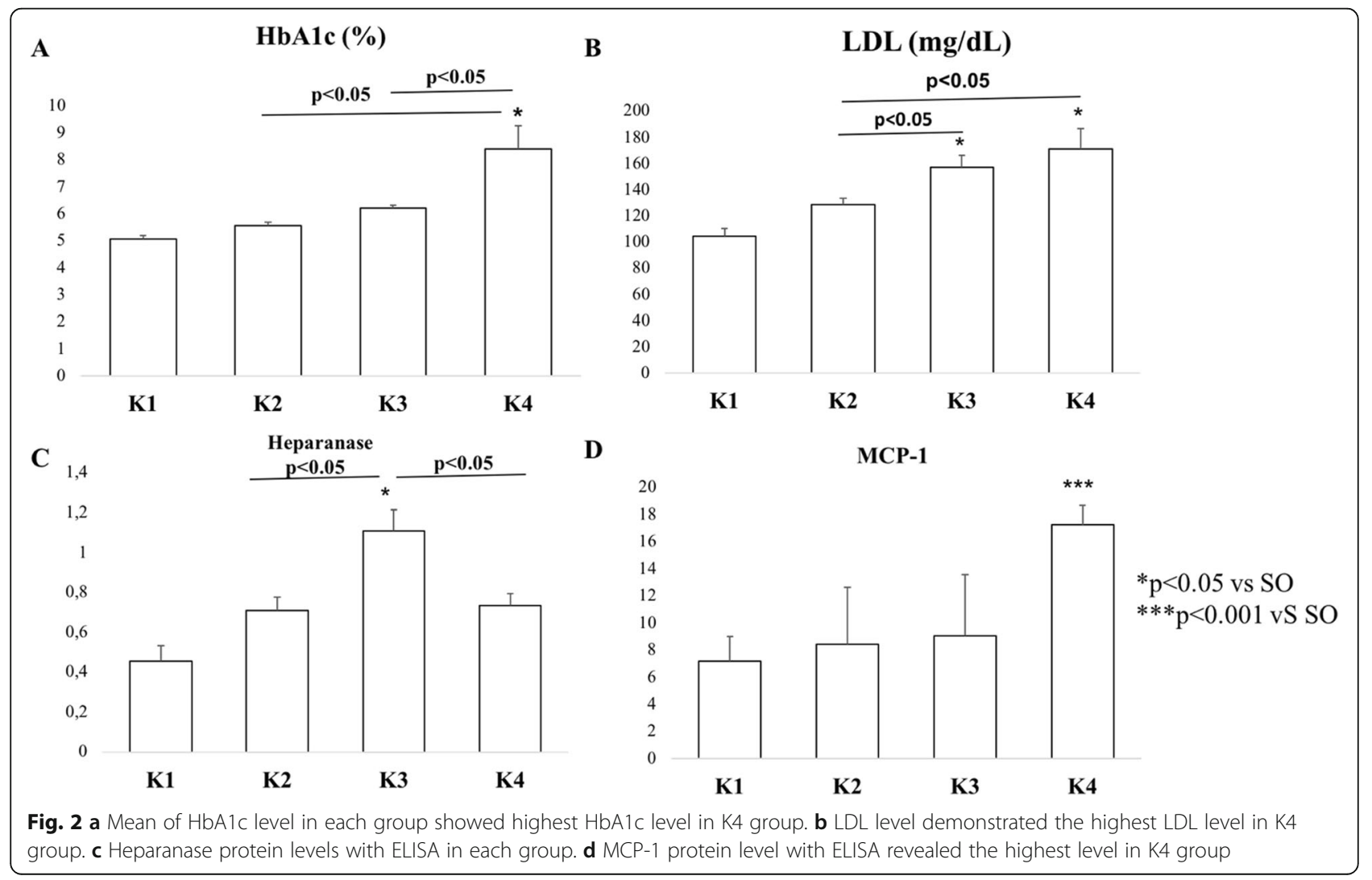




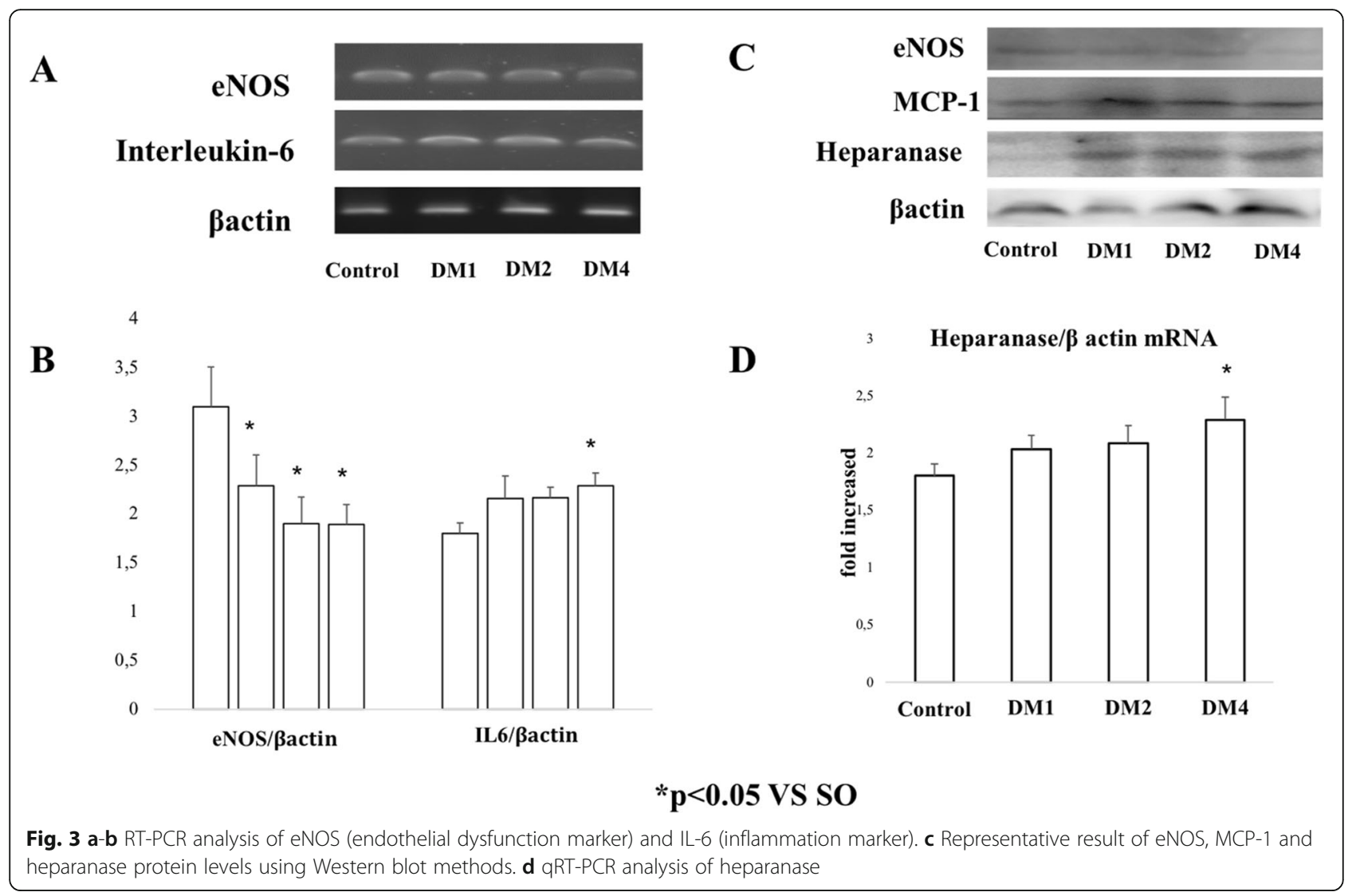

\section{Discussion}

This study reveals inflammation with endothelial injury occurs more in populations with obesity and high glucose levels. This condition may be associated with deterioration of fatty lipids with increasing LDL, triglycerides and cholesterol levels. Remarkably, Heparanase, an enzyme that can cleave the Heparan sulphate (HS) proteoglycan begins to increase in prediabetic condition. Patients with diabetes mellitus (DM) are at higher risk for many diseases such as cardiovascular diseases, peripheral arterial diseases, cerebrovascular diseases and chronic kidney diseases. These diseases lead to end stage organ damage such as retinopathy, nephropathy, and neuropathy $[6,28]$.
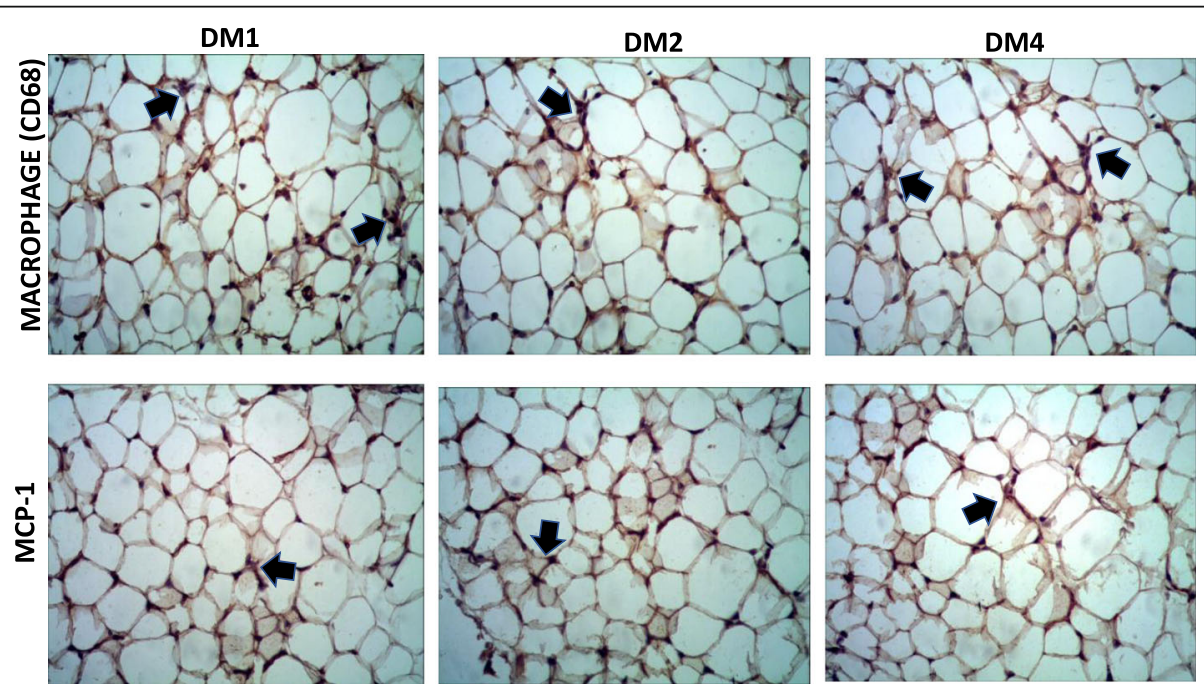

Fig. 4 Immunostaining of CD68 and MCP-1 in adipose tissue (black arrows). The black arrows show the positive cells 
Obesity may correlate with increased blood glucose levels and inflammation. Obesity stimulates extrication of proinflammatory cytokines and chemokines causing insulin resistance. The excesses of insulin resistance give numerous impacts such as an increase of free fatty acid (FFA) from adipocyte tissue to endothelial cells. The increase of FFA leads to the production of reactive oxygen species (ROS) which activates either AGE, PKC, or hexosamine (GlcNAc) pathways or nuclear factor kappa beta $(\mathrm{NFkB})$. Various pathways induce production of inducible nitric oxide synthase (iNOS), which contributes to the insulin resistance. Proinflammatory cytokines and chemokines, especially MCP-1, expressed by adipocyte cells, endothelial cells, and monocyte induce an increase of macrophage numbers $[29,30]$.

Proinflammatory cytokine and chemokine-induced by obesity stimulates sterile chronic inflammation which augments cellular senescence $[7,31]$. The combination of hyperglycemia, insulin resistance, and chronic inflammation induced endothelial dysfunction, moreover macrovasculopathy. Endothelial cells (EC) may become the most susceptible cell to be injured in this condition. Hayasi (2006) showed that there is an attenuation of eNOS protein and augmentation of reactive oxygen species (ROS) in Human Umbilical Vascular Endothelial cells (HUVEC) treated with high concentration of glucose for $24 \mathrm{~h}$. This condition may associates with cellular senescence in HUVEC [32].

ELISA results showed that an increase of heparanase protein was associated with upregulation of MCP-1, an inflammatory marker and $\mathrm{HbA1}$, an endothelial glycation marker. Some examination may be needed for further study to analyze the oral glucose tolerance test and endothelial dysfunction, such as flow-mediated dilatation for endothelial dysfunction condition. Although we found that the increasing of heparanase occurred in the prediabetic conditions (as represented with K3 group), and decreased slightly in diabetic and obese conditions (represented with K4 group). Previous study demonstrated an increase of heparanase levels in diabetes patients, which can be detected in urine and plasma of the patients $[26,33]$. The hyperglycemic condition also induces heparanase expression in endothelial cells [33, 34]. In vitro studies also revealed that heparanase expression upregulates from ECs and human embryonic kidney (HEK) cells under high glucose stimulation [33, 34]. Our results also showed that the prediabetic condition in the K3 group had the highest heparanase protein level, then became lower in the $\mathrm{K} 4$ group, although the differentiation was significant and remained higher compared to the K1 group (normal/control population). This finding suggests that high glucose levels may stimulate upregulation of heparanase. Heparanase-mediated degradation of heparan sulphate affect the migration of inflammatory cells, including neutrophils, macrophages, dendritic, and mast cells, and destroy the cells [35]. Heparanase might be secreted form adipocyte based on our animal study, however we did not differentiate whether adipocyte itself or vascular cells of adipocytes that might secret heparanase. Describing the source of heparanase in adipocyte may give better understanding for further study. Previous study found glucose was the main stimulator of heparanase, especially in rat glomerular epithelial cells and human embryonic kidney (HEK) 293 cells, which was associated with loss of HS [36]. Insulin and high glucose in obese and insulin resistance conditions might induce the heparanase upregulation [33].

\section{Conclusion}

We conclude that upregulation of heparanase in fat tissue was associated with endothelial injury and inflammation in hyperglycemia conditions.

\section{Abbreviation}

AC: Abdominal circumferrence; AGE: Advance-glycation end products; BMI: Body mass index; CD68: Cluster of differentiation 68; DM: Diabetes mellitus; EC: Endothelial cell; EDTA: Ethylenediaminetetraacetic acid; eNOS: Endothelial nitrite oxide synthase; FBG: Fasting blood glucose; FFA: Free fatty acid; GAG: Glycosaminoglycan; GlcNAc: N-Acetylglucosamine; GM-CSF: Granulocyte-macrophage colony-stimulating factors:

HbA1c: Glycated haemoglobin (A1c); HEK: Human embryonic kidney; HS: Heparan sulphate; ICAM-1: Intercellular adhesion molecule-1: IL6: Interleukin-6; iNOS: Inducible nitrite oxide synthase; IRI: Ischemic reperfussion injury; LDL: Low density lipoprotein; MCP-1: Monocyte chemoattractant protein-1; MIP: Macrophage inflammatory proteins; NF $K$ B: Nuclear factor kappa beta; PAI-1: Plasminogen activated inhibitor-1; qRTPCR: Quantitative real time polymerase chain reaction; RAS: Reninangiotensin system; RNA: Ribonucleic acid; ROS: Reactive oxygen species; RTPCR: Reverse transcriptase polymerase chain reaction; SASP: Senescenceassociated secretory phenotype; SDS-PAGE: Sodium duodecyl sulphate-Poly acrylamide gel electrophoresis; TBST: Tris buffer saline with Tween20

\section{Acknowledgments}

We extend our thanks to Mr. Mulyana and Mrs. Krisna Wulandari for their assistance while doing the population study, Ms. Luh Cynthia Catur Fatmawati for assisting with RT-PCR and IHC staining experiments, and Mrs. Sri Nuryani for assisting in ELISA quantification.

\section{About this supplement \\ This article has been published as part of BMC Proceedings Volume 13 Supplement 11, 2019: Selected articles from the 3rd International Symposium on Congenital Anomaly and Developmental Biology 2019 (ISCADB 2019). The full contents of the supplement are available online at https://bmcproc. biomedcentral.com/articles/supplements/volume-13-supplement-11.}

\section{Authors' contribution}

NA carried out design of the study and drafted the manuscript. NA, WA, MR and DC carried out the population study. WA and DC performed RT-PCR analysis and immunohistochemistry analysis. All the authors approve the final manuscript.

\section{Funding}

This research was funded by Nutrifood Research Center (NRC) Grant 2017 2018. Publication was funded by Faculty of Medicine, Public Health and Nursing, Universitas Gadjah Mada, Indonesia.

Availability of data and materials

All data generated or analysed during this study are included in the submission. The raw data are available from the corresponding author on reasonable request. 


\section{Ethics approval and consent to participate}

This study has been approved by the Ethical Committee of the Faculty of Medicine, Public Health, and Nursing Universitas Gadjah Mada/Dr. Sardjito Hospital with ethical expediency number KE/FK/0490/EC/2018. All of the participants have been agreed on joining the study. Informed consent has been signed by the participants before joining the study.

\section{Consent for publication}

Not applicable.

\section{Competing interests}

The authors declare that they have no competing interests.

Published: 16 December 2019

\section{References}

1. W. H. Organization. Global report on diabetes. Glob Rep Diabetes. 2016; pp. 9-21.

2. Knowler WC, et al. 10-year follow-up of diabetes incidence and weight loss in the diabetes prevention program outcomes study. Lancet. 2011; 374(9702):1677-86.

3. DeFrozo R. Dysfunctional fat cells, lipotoxicity and type 2 diabetes. Int J Clin Pr Suppl. 2004;143:9-21.

4. Martyn JAJ, Kaneki M, Yasuhara S. Obesity-induced insulin resistance and hyperglycemia: etiological factors and molecular mechanisms. Anesthesiology. 2014;109(1):137-48

5. Montague CT, Prins JB, Sanders L, Zhang J, Sewter CP, Byrne CD, et al. Depot-related gene expressionin human subcutaneus and omental adipocytes. Diabetes. 1998;47:1384-91.

6. Cade WT. Diabetes special issue diabetes-related microvascular and macrovascular diseases in the physical therapy setting. Phys Ther. 2008; 88(11):1322-35.

7. Palmer AK, Tchkonia T, Lebrasseur NK, Chini EN. Cellular senescence in type 2 diabetes : a therapeutic opportunity. Diabetes. 2015;64:2289-98.

8. Cao Q, Harris DCH, Wang Y. Macrophages in kidney injury, inflammation, and fibrosis. Physiology. 2015;30(3):183-94.

9. Prattichizzo F, De Nigris V, La Sala L, Procopio AD, Olivieri F, Ceriello A. "inflammaging" as a druggable target: a senescence-associated secretory phenotype - centered view of type 2 diabetes. Oxid Med Cell Longev. 2016;2016:1-6

10. Brodsky SV, Yamamoto T, Tada T, Kim B, Chen JUN, Kajiya F, et al. Endothelial dysfunction in ischemic acute renal failure : rescue by transplanted endothelial cells. Am J Physiol Ren Physiol. 2002;282(10595): F1140-9.

11. Van Golen RF, Van Gulik TM, Heger M. Free radical biology \& medicine mechanistic overview of reactive species-induced degradation of the endothelial glycocalyx during hepatic ischemia/reperfusion injury. Free Radic Biol Med. 2012;52(8):1382-402.

12. Ishiharajima S, Aida T, Nakagawa R, Kameyama K, Sugano K, Oguro T, et al. Damage during Ischemia in rat heart. Exp Mol Pathol. 1986:44:1-6.

13. Beresewicz A, Czarnowska E, Maczewski M. Ischemic preconditioning and superoxide dismutase protect against endothelial dysfunction and endothelium glycocalyx disruption in the postischemic Guinea-pig hearts. Mol Cell Biochem. 1998;186(1-2):87-97.

14. Ward BJ, Donnelly JL. Hypoxia induced disruption of the cardiac endothelial glycocalyx: implications for capillary permeability. Cardiovasc Res. 1993;27: 384-9.

15. Lipowsky HH, Gao L, Lescanic A, Lipowsky HH, Gao L, Lescanic A. Shedding of the endothelial glycocalyx in arterioles, capillaries, and venules and its effect on capillary hemodynamics during inflammation shedding of the endothelial glycocalyx in arterioles, capillaries, and venules and its effect on capillary hemo. Am J Physiol Hear Circ Physiol. 2012;301(310):H2235-45.

16. Mulivor AW, Lipowsky HH. Inflammation- and ischemia-induced shedding of venular glycocalyx. Am J Physiol Hear Circ Physiol. 2004;286:H1672-80.

17. Salmon AHJ, Satchell SC. Endothelial glycocalyx dysfunction in disease : albuminuria and increased microvascular permeability. J Pathol. 2012; 226:562-74

18. Jeansson M, Bjo K, Tenstad O. Adriamycin alters glomerular endothelium to induce proteinuria. J Am Soc Nephrol. 2009;20:114-22.

19. Rao G, Ding HG, Huang W, Le D. Reactive oxygen species mediate high glucose-induced heparanase-1 production and heparan sulphate proteoglycan degradation in human and rat endothelial cells : a potential role in the pathogenesis of atherosclerosis. Diabetol. 2011;54:1527-38.

20. Arfian N, Sari DCR, Romi MM, Wibisono DP, Emoto N. Heparanase expression in renal interstitial may contribute to epithelial and endothelial cells injuries after kidney ischemic/ reperfusion episode in mice. KnE Life Sci. 2015;2:70-7.

21. Cohen I, Pappo O, Elkin M, San T, Bar-shavit R, Hazan R, et al. Heparanase promotes growth, angiogenesis and survival of primary breast tumors. Int J Cancer. 2006;1617:1609-17.

22. Ilan N, Elkin M, Vlodavsky I. Regulation, function and clinical significance of heparanase in cancer metastasis and angiogenesis. Int J Biochem Cell Biol. 2018:38:2018-39.

23. Purushothaman A, Chen L, Yang Y, Sanderson RD. Heparanase stimulation of protease expression implicates it as a master regulator of the aggressive tumor phenotype in myeloma. J Biol Chem VOL. 2008;283(47):32628-36.

24. Koliopanos A, Friess H, Shi X, Liao Q, Pecker I, Vlodavsky I, et al. Advances in brief heparanase expression in primary and metastatic pancreatic cancer 1. Cancer Res. 2001;61:4655-9.

25. Gil N, Goldberg R, Neuman T, Garsen M, Zcharia E, Rubinstein AM, et al. Heparanase is essential for the development of diabetic. Diabetes. 2012; 61(1):208-16

26. Maxhimer JB, Somenek M, Rao G, Pesce CE, Baldwin D, Gattuso P, et al. Heparanase-1 gene expression and regulation by high glucose in renal epithelial cells. Diabetes. 2005;54(July):2172-8.

27. Moreno B, Paula A, Buonalumi L, Yugar T, Elaine S, Amorim FR, et al. Glycated hemoglobin correlates with arterial stiffness and endothelial dysfunction in patients with resistant hypertension and uncontrolled diabetes mellitus. J Clin Hypertens. 2018;20(March):910-7.

28. Alberti KGMM, Zimmet PZ. Definition, diagnosis and classification of diabetes mellitus and its complications. Part 1: diagnosis and classification of diabetes mellitus provisional report of a WHO consultation. Diabet Med. 1998;15(7):539-53.

29. Kahn SE, Hull RL, Utzschneider KM. Mechanisms linking obesity to insulin resistance and type 2 diabetes. Nature. 2006:444(7121):840-6.

30. Brownlee $M$. The pathobiology of diabetic complications: a unifying mechanism. Diabetes. 2005:54(6):1615-25.

31. Hardya OT, Czecha MP, Corveraa S. What causes the insulin resistance underlying obesity? Curr Opin Endocrinol Diabetes Obes. 2012;19(2):81-7.

32. Hayashi T, Matsui-Hirai H, Miyazaki-Akita A, Fukatsu A, Funami J, Ding Q-F, et al. Endothelial cellular senescence is inhibited by nitric oxide: implications in atherosclerosis associated with menopause and diabetes. Proc Natl Acad Sci. 2006;103(45):17018-23.

33. Shafat I, Ilan N, Zoabi S, Vlodavsky I, Nakhoul F. Heparanase levels are elevated in the urine and plasma of type 2 diabetes patients and associate with blood glucose levels. PLoS One. 2011:6(2):1-8.

34. Wang F, Kim MS, Puthanveetil P, Kewalramani G, Deppe S, Ghosh S, et al. Endothelial heparanase secretion after acute hypoinsulinemia is regulated by glucose and fatty acid. Am J Physiol Hear Circ Physiol. 2019;296:1108-16.

35. Simeonovic CJ, Ziolkowski AF, Wu Z, Choong FJ, Freeman C, Parish CR. Heparanase and autoimmune diabetes. Immunology. 2013;4:1-7.

36. Van Den Hoven MJ, Rops AL, Bakker MA, Aten J, Rutjes N, Roestenberg P, et al. Increased expression of heparanase in overt diabetic nephropathy. Kidney Int. 2006;70(12):2100-8.

\section{Publisher's Note}

Springer Nature remains neutral with regard to jurisdictional claims in published maps and institutional affiliations.

Ready to submit your research? Choose BMC and benefit from:

- fast, convenient online submission

- thorough peer review by experienced researchers in your field

- rapid publication on acceptance

- support for research data, including large and complex data types

- gold Open Access which fosters wider collaboration and increased citations

- maximum visibility for your research: over $100 \mathrm{M}$ website views per year

At $\mathrm{BMC}$, research is always in progress.

Learn more biomedcentral.com/submissions 